the maximum dose permitted in current guides. Their calculation of up to 27,000 cases of genetic defects or diseases per year should be viewed in the light of estimates that the US population dose is unlikely to exceed $1 \%$ of the current guide levels.

The International Commission on Radiation Units and Measurements (ICRU) was represented by its Chairman, H. O. Wyckoff, who announced their intention to retain a special unit (the rem) for the quantity of Dose Equivalent. In spite of the temptation of the Système International and in the face of the logic of those who regard the unit as an expression of risk, the ICRU will retain the rem as an aid to clear and safe communication. W. S. Snyder (Oak Ridge National Laboratory) gave advance warning of ICRP changes in internal radiation dose concepts and said that the Maximum Permissible Annual Intake would be used in future as a quantity directly related to the annual dose received. The appropriate ICRP reports are being re-issued and these will give derived limits for occupational exposure to airborne radioactive contamination.

The meaning of the congress and association title is now taken to embrace non-ionising radiation. This topic was reviewed by $\mathbf{H}$. Jammet (Commisariat a l'Énergie Atomique, France) who discussed the hazards of microwave and ultraviolet radiation as well as the potential damage caused by laser beams. $\mathrm{He}$ was able to quote some safe exposure levels for these radiations but had found no equivalent to the ICRP and reported that there is a lack of satisfactory radiation monitoring systems and in some cases biological data are inadequate.

\section{FOREST ECOLOGY \\ Nutrient Cycles}

from our Plant Ecology Correspondent SURPRISINGLY there is little reliable information regarding the rate at which various chemical elements pass through ecosystems. Such data are particularly valuable, since the pattern and rate of nutrient cycling may well be related to the productivity and the stability of some ecosystems (see, for example, Odum, Science, 164, 262; 1969). It is good to know both the overall budget of input and output of nutrients to and from a system as well as the pattern and rate of movement of nutrients within the system.

The Hubbard Brook ecosystem study in the northeastern United States has attempted to produce this information for temperate deciduous forest. Most of the information which has emerged so far from this project has been concerned with overall nutrient budgets for such elements as calcium, potassium (Ecology, 48, 772; 1967), and the way in which such budgets are modified by experimental perturbation of the system by felling and herbicide treatment $(E \mathrm{col}$. Monogr., 40, 23; 1970). The most recent paper from the Hubbard Brook study is by Eaton, Likens and Bormann (J. Ecol., $61,495 ; 1973)$ and is concerned with nutrient movement within the forest ecosystem, particularly between the forest canopy and the soil.

Eaton et al. describe the leaching of a canopy by rainfall, a process which transfers soluble material directly from the leaves and branches to the soil without the intervention of decomposer organisms. This leaching is considered as the sum of throughfall (water passing directly through the leaf canopy to the forest floor) and stemflow (water running down branches and trunks). Stemflow was found to contain a higher concentration of nutrients than throughfall, but only $5 \%$ of the total precipitation followed this path, hence its contribution to the overall leaching was small.

The total quantities of elements leached from the canopy varied from one element to another, in some cases exceeding the quantities arriving at the forest floor by litter fall. For example, potassium was leached at a rate of $30 \mathrm{~kg} \mathrm{ha}^{-1}$ between June and October, whereas annual litter fall resulted in the movement of only $21 \mathrm{~kg} \mathrm{ha}^{-1}$ of potassium from canopy to floor. The figures for sulphate sulphur are similar, $21 \mathrm{~kg} \mathrm{ha}^{-1}$ being leached during the study period, only $6 \mathrm{~kg} \mathrm{ha}^{-1} \mathrm{yr}^{-1}$ arriving at the soil surface by litter fall.

The elements quoted are usually present in ionic form, which may account for their rapid movement in solution. Elements normally occurring bound in organic molecules within plant tissues were found to be leached far more slowly. In the case of total nitrogen, $10 \mathrm{~kg} \mathrm{ha}^{-1}$ was leached from the canopy during the summer and a total of $56 \mathrm{~kg} \mathrm{ha}^{-1}$ arrived on the forest floor as litter during the year. Similarly for phosphorus (as $\mathrm{PO}_{4}^{3-}$ ), $0.68 \mathrm{~kg} \mathrm{ha}^{-1}$ was leached and $3.7 \mathrm{~kg} \mathrm{ha}^{-1} \mathrm{yr}^{-1}$ fell as litter.

In essence, these figures resemble those which Carlisle, Brown and White (J. Ecol., 54, 87; 1966) obtained from temperate deciduous forest in Britain. Eaton et al. go further than these workers in that they demonstrate the importance of hydrogen ion exchange as a mechanism in leaching cations from the canopy. The $p \mathrm{H}$ of precipitation at Hubbard Brook has a mean of 4.06; throughfall $p \mathrm{H}$ was 5.01. Hydrogen ions thus represented $74 \%$ of the cation input and only $2 \%$ of the cation loss. At least $27 \%$ of the total cation loss can be accounted for by hydrogen ion exchange. The low $p \mathrm{H}$ of the precipitation at Hubbard Brook may well derive from atmospheric pollutants since it cannot be accounted for by equilibration with atmospheric $\mathrm{CO}_{2}$. If this is so,

\title{
Formation of Cosmic Formaldehyde
}

THE discovery of the first organic molecules in space, nearly five years ago, took most astronomers by surprise because it seemed unlikely that molecules could form and survive in the harsh environment of interstellar space. But there are now twenty-six molecular species identified with reasonable certainty, and the question of the creation of these molecules has assumed some importance.

In the burgeoning subject of astrochemistry, Dalgarno and his colleagues at Harvard College Observatory have sketched some of the pathways by which the simpler molecules can be synthesised. Three months ago they pointed out (Astrophys. J. Lett., 183, L21; 1973) that positive and negative ions in interstellar clouds play an important part in the production of complex molecules. For example, the chemi-ionisation reaction $\mathrm{CH}+\mathrm{O} \rightarrow \mathrm{HCO}^{+}+e$ is an important source of ions and electrons in cosmic conditions. The presence of $\mathrm{HCO}^{+}$ can then lead to the formation of more exotic species.

In Nature Physical Science next Monday (October 15) this work is extended in a discussion of the formation of formaldehyde by Dalgarno, Oppen- heimer and Black. This molecule is one of the most widely distributed and abundant species in the Galaxy. In dense interstellar clouds one possibility is to build $\mathrm{H}_{2} \mathrm{CO}$ from $\mathrm{HCO}^{+}$. Dalgarno and his colleagues suggest, however, that the reaction $\mathrm{CH}_{3}+\mathrm{O} \rightarrow \mathrm{H}_{2} \mathrm{CO}+\mathrm{H}$ would be more likely as a source of formaldehyde in the diffuse interstellar clouds. In this picture the $\mathrm{CH}_{3}$ is built up in a three-stage process: photoionisation of carbon by starlight gives $\mathrm{C}^{+}$; this is followed by $\mathrm{C}^{+}+\mathrm{H}_{2} \rightarrow \mathrm{CH}_{2}+\mathrm{h}$, and finally $\mathrm{CH}_{2}^{+}+\mathrm{H}_{2} \rightarrow \mathrm{CH}_{3}^{+}+\mathrm{H}$ :

Although the formaldehyde itself is vulnerable to destruction by photoionisation, the authors show that for a wide range of densities and ultraviolet fluxes, the formation rate exceeds the destruction rate. A further source of formaldehyde is the reaction $\mathrm{CH}_{3}{ }^{+}+\mathrm{O} \rightarrow$ $\mathrm{H}_{2} \mathrm{CO}^{+}+\mathrm{H}$; the $\mathrm{H}_{2} \mathrm{CO}^{+}$ion then loses its positive charge through exchange with heavy elements to leave formaldehyde.

With the appearance of the results of Dalgarno et al. there seems to be no fundamental difficulty in accounting for the widespread presence of formaldehyde in the Galaxy. 